\title{
The $\eta^{6}, \eta^{1}$-Coordination of Beryllium Atoms in the Graphite Analogue $\mathrm{BeB}_{2} \mathbf{C}_{2} * *$
}

\author{
Kathrin Hofmann, Xavier Rocquefelte, Jean-François Halet, Carsten Bähtz, and Barbara Albert*
}

Dedicated to Dr. Joseph Bauer on the occasion of his 65th birthday

The coordination of beryllium ions in homoleptic beryllocene, $\left[\mathrm{Be}\left(\mathrm{C}_{5} \mathrm{H}_{5}\right)_{2}\right]$, has for decades been the subject of debate and theoretical as well as experimental investigations. It was not until quite recently that Schurko and co-workers ${ }^{[1]}$ were able to show beyond doubt that $\mathrm{Be}$ is present in $\left[\mathrm{Be}\left(\mathrm{C}_{5} \mathrm{H}_{5}\right)_{2}\right]$ in the $\eta^{5}, \eta^{1}$-coordination mode, which is consistent with the octet rule for Be. We have now found an analogous disposition for $\mathrm{Be}$ in a solid-state compound, namely $\mathrm{BeB}_{2} \mathrm{C}_{2}$, in which sixmembered rings of boron/carbon $(\mathrm{B} / \mathrm{C})$ layers coordinate to beryllium atoms in a $\eta^{6}, \eta^{1}$ fashion.

$\mathrm{BeB}_{2} \mathrm{C}_{2}$ is the first boride carbide with slipped $6^{3} \mathrm{~B} / \mathrm{C}$ layers as in graphite. Initially, we were unable to determine its structure with diffraction methods; we thus solved the structure by means of electron energy loss spectroscopy (EELS) - whereby a combination of theoretical and experimental methods was indispensable for the analysis of the energy loss near-edge structure (ELNES)—and further refinement was achieved by X-ray powder diffractometry.

This beryllium diboride dicarbide is one of two compounds that were described in the $\mathrm{Be}-\mathrm{B}-\mathrm{C}$ system about forty years ago. ${ }^{[2]}$ But although this substance was accessible as a single crystal (and its diffraction diagram was indexed in the Laue class $6 / \mathrm{mmm}, a=1082 \mathrm{pm}, c=618 \mathrm{pm}$ ), its structure had not been resolved before now. Indications from EELS ${ }^{[3]}$ that $\mathrm{BeB}_{2} \mathrm{C}_{2}$ is isostructural to $\mathrm{LiBC}$ could not be confirmed from $\mathrm{X}$-ray powder diffractometry. $\mathrm{LiBC}$ and $\mathrm{MgB}_{2} \mathrm{C}_{2}$ crystallize in layer structures in which the boron and carbon atoms form covalent, two-dimensional, planar (in analogy to the hexagonal boron nitride) or slightly corrugated networks of condensed six-membered rings. ${ }^{[4,5]}$ Similar structures are interesting in the context of the discussion of high-temperature superconductors, ${ }^{[6]}$ since they are topologically closely related to $\mathrm{MgB}_{2} \cdot{ }^{[7]}$

[*] Dr. K. Hofmann, Prof. Dr. B. Albert

Eduard-Zintl-Institut für Anorganische und Physikalische Chemie, Technische Universität Darmstadt

Petersenstrasse 18, 64287 Darmstadt (Germany)

Fax: (+49)6151-166-029

E-mail: albert@ac.chemie.tu-darmstadt.de

Dr. X. Rocquefelte, ${ }^{[+]}$Prof. Dr. J.-F. Halet

Sciences Chimiques de Rennes, UMR 6226

CNRS-Université de Rennes 1 (France)

Dr. C. Bähtz

Hasylab/Desy (Germany) (now at ESRF, France)

$\left.{ }^{+}\right]$Present address: Institut des Matériaux Jean Rouxel, UMR 6502, CNRS-Université de Nantes (France)

[***] We thank the Deutsche Forschungsgemeinschaft for financial support and Dr. K. Schmitt for preparatory work.
We were recently able to show that it is possible to distinguish between several possible structural models for $\mathrm{MB}_{2} \mathrm{C}_{2}$ compounds $(\mathrm{M}=\mathrm{Ca}, \mathrm{La})$ by comparing the experimental fine-edge structures of the $\mathrm{B}_{\mathrm{K}}$ ionization edges with those obtained by DFT calculations. ${ }^{[8]}$ This result was later confirmed by independent DFT calculations. ${ }^{[9]}$ The fine-edge structure of the $\mathrm{B}_{\mathrm{K}}$ edge in borides and boride carbides is highly variable with respect to weak structural and electronic influences. $^{[10]}$

The work described herein derives an otherwise inaccessible, coherent structural model for $\mathrm{BeB}_{2} \mathrm{C}_{2}$ by calculating the energy loss near-edge structures (obtained with the WIEN2k software $)^{[11]}$ for a number of atomic distributions. The structure was then refined on the basis of X-ray powder diffractograms and confirmed by theoretical quantum calculations.

We were able to obtain $\mathrm{BeB}_{2} \mathrm{C}_{2}$ in the form of a crystalline powder at a temperature of $1950^{\circ} \mathrm{C}$. With EELS, the $\mathrm{Be} / \mathrm{B} / \mathrm{C}$ ratios were established to be 1:2:2. The diffractograms, which were obtained by high-resolution Guinier diffractometry and $\mathrm{Cu}_{\mathrm{K} \alpha 1}$ irradiation (flat specimen, transmission) as well as on the synchrotron (Hasylab, DESY, $\lambda=113.96101 \mathrm{pm}, \mathrm{Ge}(111)$ double monochromator, Ge(111) analyzer, capillaries, Debye-Scherrer geometry), did not permit us to find a solution for the structure. ${ }^{[12]}$ Although it was possible to index the diffractograms for the first time in an orthorhombic crystal system similarly to those of magnesium diboride dicarbide (space group no. 64, Cmce, $a=1083.7, b=939.6, c=$ $613.6 \mathrm{pm}$; compare $\mathrm{MgB}_{2} \mathrm{C}_{2}: a=1092.2, \quad b=946.1, \quad c=$ $745.9 \mathrm{pm}$ ), the distortions of the network obtained by Rietveld refinement of the analogous structural model did not make sense, and the difference Fourier maps for the structure model without cations showed no atomic positions for the beryllium atoms.

The measured $\mathrm{B}_{\mathrm{K}}$ ionization edges of the compounds LiBC, $\mathrm{MgB}_{2} \mathrm{C}_{2}$, and $\mathrm{BeB}_{2} \mathrm{C}_{2}$ are very similar to one another (Figure 1). If one calculates the $\mathrm{B}_{\mathrm{K}}$ fine-edge structures of $\mathrm{LiBC}$ and $\mathrm{MgB}_{2} \mathrm{C}_{2}$ on the basis of structures described in the literature and then compares these with the experimental ELNES, the agreement is very convincing (Figure 2a,b). On the other hand, the structural models of $\mathrm{LiBC}$ and $\mathrm{MgB}_{2} \mathrm{C}_{2}$ do not allow a correct simulation of the experimental $\mathrm{B}_{\mathrm{K}}$ ELNES of $\mathrm{BeB}_{2} \mathrm{C}_{2}$ (Figure $2 \mathrm{c}$ ). As soon as the $\mathrm{B} / \mathrm{C}$ layers are slipped with respect to each other, however, to make a $\mathrm{B} / \mathrm{C}$ arrangement analogous to that of graphite, the agreement becomes striking between the ELNES calculated on the basis of this structural model and the experimental one. This is true for the $B_{K}$ as well as for the $C_{K}$ ionization edges (Figure $3 a, b$ ). One 


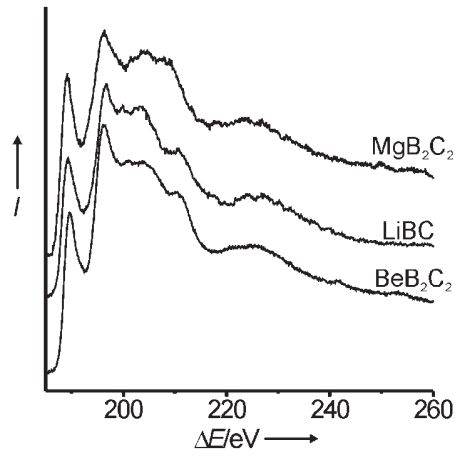

Figure 1. $B_{K}$ ionization edges for $B_{e} B_{2} C_{2}$ (bottom), $L i B C$ (middle), and $\mathrm{MgB}_{2} \mathrm{C}_{2}$ (top).

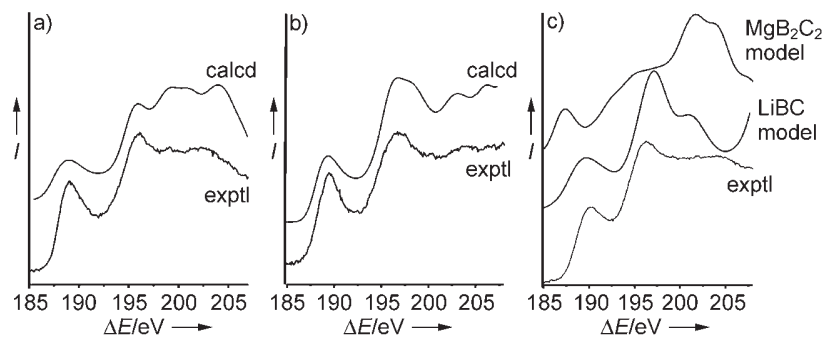

Figure 2. Experimental (bottom) and calculated (top) $B_{k}$ ELNES for $\mathrm{LiBC}$ (a), $\mathrm{MgB}_{2} \mathrm{C}_{2}$ (b), and $\mathrm{BeB}_{2} \mathrm{C}_{2}$ (c), calculated using known structure models.
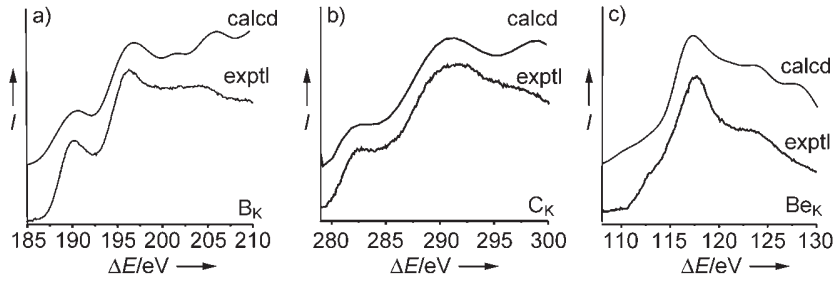

Figure 3. Experimental (bottom) and calculated (top) $B_{K}(a), C_{K}(b)$, and $\mathrm{Be}_{\mathrm{K}}$ (c) ELNES for $\mathrm{BeB}_{2} \mathrm{C}_{2}$.

carbon atom of the first layer has to be located above or below the center of a six-membered ring of the second layer, leading to a structure with the space group Pmmn $(a=613.425(5) \mathrm{pm}$, $b=542.20(3) \mathrm{pm}, c=469.28(3) \mathrm{pm})$, with $\mathrm{B}$ and $\mathrm{C}$ on one fourfold and two twofold positions each. This structural model is amenable to refinement by the Rietveld method on the basis of synchrotron data (GSAS software ${ }^{[12 b]}$ ), and the analysis of the difference Fourier maps shows electron density on a $4 f$ site which corresponds to the position of the beryllium atoms. The complete structure model allows a calculation even of the $\mathrm{Be}_{\mathrm{K}}$ ionization edge, which matches the experimental edge quite well (Figure $3 \mathrm{c}$ ). All positional coordinates and common displacement parameters for each of the elements can be freely refined and lead to a good adjustment of the experimental diffraction data (Figure 4). ${ }^{[13]}$ The B/C layers are planar, as shown in Figure 5. The $\mathrm{B}-\mathrm{C}$ distances are between 154.4(3) and 159.4(3) pm and can thus be compared to $\mathrm{B}-\mathrm{C}$ distances in other compounds with $\mathrm{B} / \mathrm{C}$ layers, for example, $\mathrm{CaB}_{2} \mathrm{C}_{2}{ }^{[14]}$ The $\mathrm{Be}$ ions are $\eta^{6}$-coordinated on one side by three $\mathrm{B}$ and three $\mathrm{C}$ atoms of one layer, and bound to only one $\mathrm{C}$ atom on the other side with a $\mathrm{Be}-\mathrm{C}$ distance of

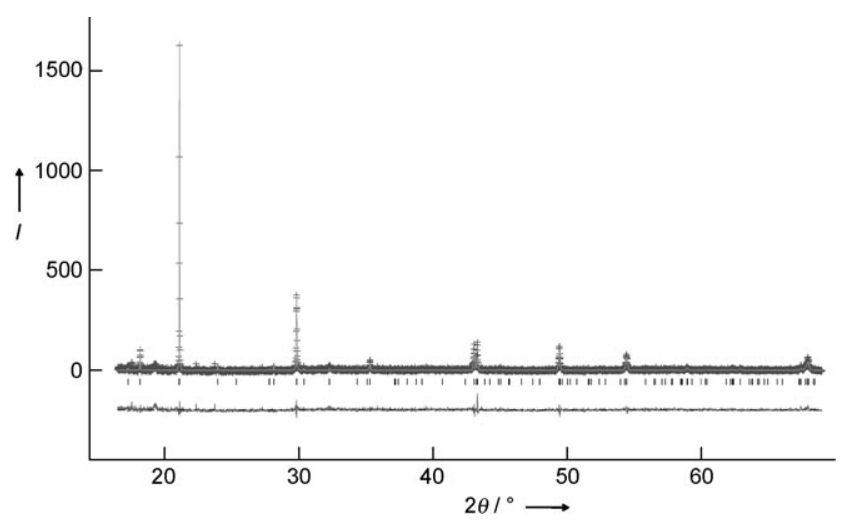

Figure 4. Observed $(+)$ and calculated (solid line) powder pattern for $\mathrm{BeB}_{2} \mathrm{C}_{2}$ with the difference curve (bottom). The vertical dashes indicate the positions of the reflections. $I=$ intensity.
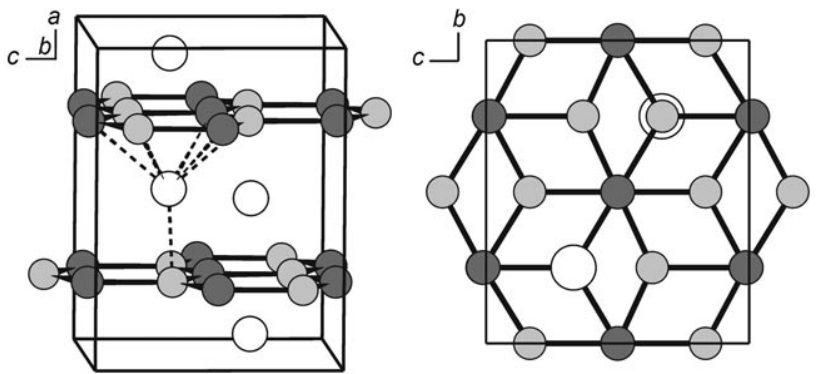

Figure 5. Projection of the unit cell along the crystallographic $b$ axis (left) and along the crystallographic $a$ axis (right). Be white, B dark gray, $\mathrm{C}$ light gray.

181.1(1) pm (Figure 5), which is significantly shorter than the three other $\mathrm{Be}^{-} \mathrm{C}$ distances (196.3(2)-197.5(2) pm) and the three $\mathrm{Be}-\mathrm{B}$ distances (201.8(2)-206.8(2) pm). This $\eta^{1}$-coordination mode may be described as a $\sigma \mathrm{Be}-\mathrm{C}$ bond, similarly to that described for $\left[\mathrm{Be}\left(\eta^{1}-\mathrm{C}_{5} \mathrm{H}_{5}\right)\left(\eta^{5}-\mathrm{C}_{5} \mathrm{H}_{5}\right)\right] \cdot{ }^{[15]}$

Comparative DFT calculations ${ }^{[16]}$ for the geometry-optimized structure models in Pmmn (this work) and Cmce $\left(\mathrm{MgB}_{2} \mathrm{C}_{2}\right.$-like) show, as mentioned above, an energy preference for the former (514 meV per formula unit). Indeed, full geometric optimizations of the two arrangements with no symmetry imposed indicate that the structure with initial Cmce symmetry strongly distorts towards a more stable arrangement (of $P 2_{1} / c$ symmetry) in which the atomic connectivity of the $\mathrm{Be}$ atoms is reduced and comparable to that observed in the structure with Pmmn symmetry. Calculations on a structure with initial Pmmn symmetry, however, lead to hardly any modification of the geometry. This result shows unambiguously that the $\eta^{6}, \eta^{1}$-coordination mode of $\mathrm{Be}$ is strongly energetically favored over the $\eta^{6}, \eta^{6}$ mode in $\mathrm{BeB}_{2} \mathrm{C}_{2}$. With a computed band gap of about $1 \mathrm{eV}, \mathrm{BeB}_{2} \mathrm{C}_{2}$ is expected to be an electrical semiconductor.

The density of states (DOS) of $\mathrm{BeB}_{2} \mathrm{C}_{2}$ is compared for both space groups, Pmmn and Cmce, in Figure 6. The stability of the Pmmn structure is directly related to the nature and the number of the states at the Fermi level $\left(\varepsilon_{\mathrm{F}}\right)$. Examination of the projected DOS indicates that the participation of beryllium is weaker around $\varepsilon_{\mathrm{F}}$ for the slipped-sandwich $\eta^{6}, \eta^{1}$ arrangement than for the symmetrical-sandwich $\eta^{6}, \eta^{6}$ arrangement. In other words, just the existence of a band 


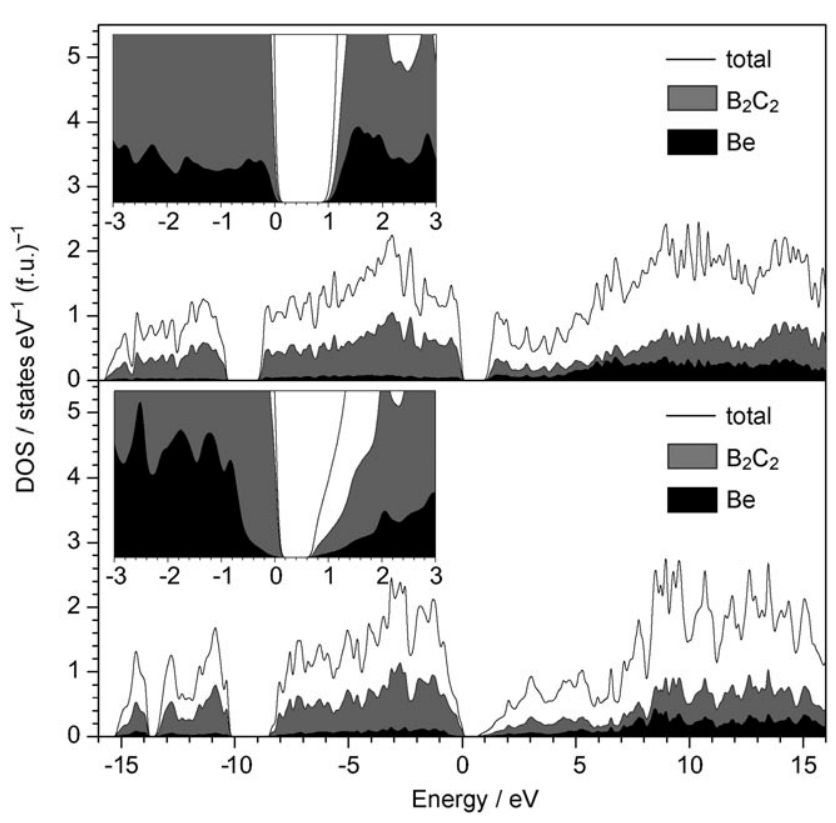

Figure 6. Total and projected densities of states of $\mathrm{BeB}_{2} \mathrm{C}_{2}$ with $\mathrm{Cmce}$ (top) and Pmmn (bottom) symmetry. The Fermi-level region is enlarged in the inset. f.u. = formula unit.

gap does not explain the higher stability of the Pmmn model for $\mathrm{BeB}_{2} \mathrm{C}_{2}$ with respect to the Cmce model. Both structures exhibit a band gap at $\varepsilon_{\mathrm{F}}$, consistent with the "Zintl formula" $\left[\mathrm{Be}^{2+}\left(\mathrm{B}_{2} \mathrm{C}_{2}\right)^{2-}\right]$. The Pmmn structure gains additional stability from the $\eta^{1} \mathrm{Be}-\mathrm{C}$ bonding interactions, which strengthen the covalent character of the compound, and from the lower steric repulsion between the $\mathrm{B} / \mathrm{C}$ layers, as in beryllocene. ${ }^{[15]}$ Stronger covalent interactions between $\mathrm{Be}$ and the $\mathrm{B} / \mathrm{C}$ layers lead to some destabilization in energy of the $B e^{-}-\mathrm{B} / \mathrm{C}$ antibonding states and some stabilization of the bonding states, thus diminishing the DOS around $\varepsilon_{\mathrm{F}}$.

This is thus the first solution of a crystal structure by the unusual combination of the two methods "theory-supported ELNES" and "high-resolution powder diffractometry". The stability of the crystal structure determined in this way is supported by theoretical calculations. The structural chemistry of $\mathrm{BeB}_{2} \mathrm{C}_{2}$ is the first of a compound in the $\mathrm{Be}-\mathrm{B}-\mathrm{C}$ system to be determined, which also reveals a fascinating analogy between the molecular and solid-state chemistry of beryllium.

\section{Experimental Section}

Caution: Beryllium and beryllium compounds are highly toxic and may act as human carcinogens. Handling of such substances should only be performed in consideration of the required safety precautions.

The samples were synthesized from the elements according to the desired stoichiometry $\mathrm{Be} / \mathrm{B} / \mathrm{C}=1: 2: 2$. The starting mixtures were prepared under argon in a glovebox, pressed into pellets, and heated for $1 \mathrm{~h}$ to $1950^{\circ} \mathrm{C}$ in an induction furnace (BN crucible inside a graphite crucible).
Keywords: beryllium - borides · density functional calculations . ELNES (energy loss near-edge structure analysis) . powder diffractometry

[1] a) I. Hung, C. L. B. Macdonald, R. W. Schurko, Chem. Eur. J. 2004, 10, 5923-5935; b) the structure of crystalline $\left[\mathrm{Be}\left(\eta^{1}-\right.\right.$ $\left.\left.\mathrm{C}_{5} \mathrm{H}_{5}\right)\left(\eta^{5}-\mathrm{C}_{5} \mathrm{H}_{5}\right)\right]$ at $-120^{\circ} \mathrm{C}$ was first reported by: C.-H. Wong, T.-Y. Lee, K.-J. Chao, S. Lee, Acta Crystallogr. Sect. B 1972, 28, $1662-1665$.

[2] L. Ya. Markovskii, N. V. Vekshina, Yu. D. Kondrashev, I. M. Stronganova, J. Appl. Chem. 1966, 39, 10-16; Zh. Prikl. Khim. 1966, 39, $13-20$.

[3] L. A. J. Garvie, P. R. Buseck, P. Rez, J. Solid State Chem. 1997, $133,347-355$

[4] M. Wörle, R. Nesper, G. Mair, M. Schwarz, H. G. von Schnering, Z. Anorg. Allg. Chem. 1995, 621, 1153-1159.

[5] M. Wörle, R. Nesper, J. Alloys Compd. 1994, 216, 75-83.

[6] J. Nagamatsu, N. Nakagawa, T. Muranaka, Y. Zenitani, J. Akimitsu, Nature 2001, 410, 63-64.

[7] M. E. Jones, R. E. Marsh, J. Am. Chem. Soc. 1954, 76, $1434-$ 1436.

[8] K. Hofmann, B. Albert, ChemPhysChem 2002, 3, 896-898.

[9] X. Rocquefelte, S.-E. Boulfelfel, M. Ben Yahia, J. Bauer, J.-Y. Saillard, J.-F. Halet, Angew. Chem. 2005, 117, 7714-7717; Angew. Chem. Int. Ed. 2005, 44, 7542-7545.

[10] K. Hofmann, R. Gruehn, B. Albert, Z. Anorg. Allg. Chem. 2002, 628, 2691-2696.

[11] a) P. Blaha, K. Schwarz, G. K. H. Madsen, D. Kvasnicka, L. Luitz, WIEN2k: An Augmented Plane Wave + Local Orbitals Program for Calculating Crystal Properties, Technische Universität Wien, Wien, 2001; b) C. Hébert-Souche, P.-H. Louf, P. Blaha, M. Nelhiebel, J. Luitz, P. Schattschneider, K. Schwarz, B. Jouffrey, Ultramicroscopy 2000, 83, 9-16.

[12] a) K. Schmitt, Dissertation, University of Giessen, 2000, b) A. C. Larson, R. B. Von Dreele, Program GSAS, Los Alamos (USA) 1985.

[13] Structure refinement of $\mathrm{BeB}_{2} \mathrm{C}_{2}$ : orthorhombic, space group Pmmn (no. 59), $a=613.425(5), b=542.20(3), c=469.28(3) \mathrm{pm}$, $\rho_{\text {calcd }}=2.327 \mathrm{~g} \mathrm{~cm}^{-3}, Z=4,104$ reflections, 13 refined positional and displacement parameters, $R_{\mathrm{wp}}=0.2726, R_{\mathrm{p}}=0.2077, D_{\mathrm{wd}}=$ $1.427, \chi^{2}=1.491$. Further details on the crystal structure investigations may be obtained from the Fachinformationszentrum Karlsruhe, 76344 Eggenstein-Leopoldshafen, Germany (fax: (+49)7247-808-666; e-mail: crysdata@fiz-karlsruhe.de), on quoting the depository number CSD-418618.

[14] B. Albert, K. Schmitt, Inorg. Chem. 1999, 38, 6159-6163.

[15] a) E. D. Jemmis, S. Alexandratos, P. von R. Schleyer, A. Streitwieser, Jr., H. F. Schaefer III, J. Am. Chem. Soc. 1978, 100, 5695-5700; b) O. Kwon, M. L. McKee, J. Phys. Chem. A 2001, 105, 10133-10138, and references therein.

[16] Full optimizations of the atomic positions and cell parameters were carried out using the VASP code ${ }^{[17]}$ with PAW potentials. ${ }^{[18]}$ The WIEN2k code ${ }^{[11]}$ was used for calculations of the energy difference between optimized structures and for the density of states. In all calculations a PBE-generalized gradient approximation was employed for the exchange and correlation energy term. ${ }^{[19]}$

[17] G. Kresse, J. Hafner, VASP program, version 4.6, Institut für Materialphysik, Universität Wien, 2000.

[18] P. E. Blöchl, Phys. Rev. B 1994, 50, $17953-17979$.

[19] J. P. Perdew, S. Burke, M. Ernzerhof, Phys. Rev. Lett. 1996, 77, 3865-3868. 